\title{
Advances in thermal modification of joint capsular and musculoskeletal collagenous tissue
}

Kei Hayashi, Mark Markel

Kei Hayashi D.V.M., Mark D. Markel D.V.M., "Advances in thermal modification of joint capsular and musculoskeletal collagenous tissue," Proc. SPIE 10297, Matching the Energy Source to the Clinical Need: A Critical Review, 1029703 (24 January 2000); doi: 10.1117/12.375222

SPIE. Event: Digital Optical Computing, 1990, Los Angeles, United States 


\title{
Advances in thermal modification of joint capsular and musculoskeletal collagenous tissue
}

\author{
Kei Hayashi, Mark D. Markel ${ }^{*}$ \\ Comparative Orthopaedic Research Laboratory, University of Wisconsin, \\ 2015 Linden Drive West, Madison, WI 53706
}

\begin{abstract}
Thermal modification of joint capsular tissue has gained great popularity in the orthopedic community as a treatment method for joint instability since this new operative technique was introduced in 1994. Heating joint capsular tissue to approximately 60 to $80^{\circ} \mathrm{C}$ by laser or radiofrequency (RF) energy produces significant dimensional alterations (shrinkage and thickening) of the tissue treated, resulting in postoperative stabilization of the joint. Initial clinical trials in patients with shoulder instability indicated that the majority of the patients were able to return to high-level athletic performance following thermal modification of joint capsular tissue. A series of in vitro experimental studies demonstrated that the joint capsular tissue could be shortened by up to $45 \%$ through the application of laser or RF energy, although significant loss of the tissue's mechanical properties and thermal damage of the tissue were observed with higher energy applications. In vivo experimental studies demonstrated initial deleterious effects of thermal energy application, followed by an active reparative response by cellular fibrous tissue with concomitant improvement of mechanical properties. Other studies using a different animal model showed that despite significant immediate postoperative tissue shrinkage, the tissue stretches over time if the tissue is subjected to physiological loading. Based on these scientific studies, it is proposed that thermal modification of joint capsular tissue relies not only on the initial effect (shrinkage), but to a great extent, the tissue's biological response (repair of the thermally modified tissue with new thicker tissue) to achieve postoperative joint stability. Currently, arthroscopic thermal modification of shoulder joint capsular tissue is performed clinically at many hospitals, with generally good to excellent outcomes to date. Development and improvement of thermal energy delivery devices are actively being investigated for various clinical applications. Recently, the treatment of other joint disorders such as patellar instability have been examined. In addition, the potential for thermal modification of other musculoskeletal tissues such as cartilage is being explored. Thermal modification of musculoskeletal tissues have the potential to enhance joint stability and may become a prominent modality in the treatment of joint disorders. However, it should be emphasized that thermal treatment does cause initial deleterious effects on the tissue's properties, and that long term results have yet to be evaluated. Carefully controlled clinical and scientific studies should further clarify the advantages and disadvantages of this technique.
\end{abstract}

Keywords: Joint instability, thermal modification, laser, radiofrequency, joint capsule, ligament, collagen, fibroblasts, wound healing, tissue remodeling

${ }^{*}$ Correspondence: Email: markelm@svm.vetmed.wisc.edu; Telephone: 608262 3573; Fax: 608265 


\section{INTRODUCTION: BACKGROUND AND SIGNIFICANCE}

Efforts in the area of thermal modification of musculoskeletal soft tissues began in 1993 when a group of orthopedic surgeons in Utah and California noted shrinkage of glenohumeral joint capsular tissue when it was inadvertently treated in a defocused manner using the Holmium:YAG (Ho:YAG) laser. Application of Ho:YAG laser energy to a tissue in contact or near contact modes results in tissue ablation and cutting, whereas application of laser energy in a defocused manner at $1-2 \mathrm{~mm}$ from the tissue does not result in tissue ablation but instead, results in architectural changes such as shrinkage through laser's thermal effect ("nonablative" application). Following this initial discovery, a pilot clinical trial evaluating the thermal treatment of the joint capsule in patients with glenohumeral instability using nonablative Ho:YAG laser energy to shrink the capsuloligamentous tissues of glenohumeral joint under arthroscopic guidance was initiated. ${ }^{1}$ This trial subsequently demonstrated that the application of nonablative laser energy to the shoulder joint capsule dramatically shrank the capsule, stabilizing the shoulder joint in the majority of the patients treated. Based on the findings of this study, we hypothesized that thermal modification of dense collagenous tissues such as joint capsule, ligament, and tendon may allow precise alteration of these tissues' structural properties, thereby enhancing joint function and providing therapeutic benefits for joint instability and related symptoms.

\subsection{Background}

Glenohumeral shoulder instability is a common and recurring problem particularly in the young or athletic patient. ${ }^{2-5}$ Multidirectional and unidirectional glenohumeral instability secondary to ligamentous laxity, capsular redundancy, and excessive joint volume is a frequent occurrence that current closed, open, and arthroscopic treatments do not satisfactorily address. ${ }^{6-11}$ Physical therapy, open surgical techniques, and arthroscopic techniques either do not achieve adequate stability in most patients (physical therapy, arthroscopy) or else severely limit function (open techniques), so that patients are not able to return to their previous level of activity or performance after treatment. ${ }^{2,5,7,8,12-14}$ Therefore, there appears to be a need for a simply performed, low morbidity procedure that eliminates capsular redundancy, diminishes joint volume, and helps stabilize shoulders of patients, allowing individuals to return to their previous level of activity or performance. Laser, an acronym for light amplification by the stimulated emission of radiation, transmits energy efficiently in the form of an intense beam of light. Light energy of laser absorbed by the tissue is transformed into effective thermal energy. ${ }^{15}$ Recent scientific studies evaluating laser energy for tissue welding and thermokeratoplasty have demonstrated that long-lasting alterations of collagenous tissue architecture can be achieved by application of nonablative laser energy without a concomitant inflammatory response. ${ }^{6-18}$ Although these studies do not agree as to the exact mechanism of laser-induced alteration of collagenous tissue properties, investigators do agree that the effect is primarily caused by the thermal effect of laser energy. The thermal properties of collagen have been extensively studied in a variety of experimental models and thermal shrinkage of collagen is a well-described phenomenon. ${ }^{19-26}$

\subsubsection{Joint instability and treatment}


The glenohumeral (shoulder) joint has the greatest range of motion of any joint in the human body. Functional shoulder stability is controlled by joint geometry, intraarticular pressure, ligamentous constraints, and muscle forces. ${ }^{27-29}$ Shoulder instability, which is defined as excessive glenohumeral translation that produces symptoms of instability or pain, is an important clinical problem in medicine. ${ }^{30}$ The maintenance of glenohumeral stability is dependent upon an intact capsulo-ligamentous complex and labrum (static stabilizer) as well as a neuromuscularly intact rotator cuff (dynamic stabilizer). Multidirectional and unidirectional glenohumeral instability (GHI) secondary to ligamentous laxity, capsular redundancy, and excessive joint volume are common occurences. ${ }^{6-11}$ The three typical situations where capsular redundancy can develop are atraumatic instability with minimal or no trauma, repetitive microtrauma as might occur in athletes who perform activities with the arm overhead, and acute trauma resulting in severe disruption of capsular tissues, possibly resulting in dislocation. ${ }^{31}$ The development of GHI is multifactorial and due to intrinsic and extrinsic factors. The pathologic feature common to all forms of GHI is interstitial damage, plastic deformation, and redundancy of the shoulder ligaments and capsule.

Successful treatment of GHI relies upon the identification of the direction of the instability pattern and the pathologic features which contribute to the development of a given instability pattern. The treatment of instability includes both nonoperative and operative means. Exercise programs that aim to strengthen the rotator cuff and scapular muscles are often the primary treatment for instability. The nonoperative management of instability relies upon an intensive exercise program which strengthens the dynamic muscular glenohumeral and scapulothoracic stabilizers. It would appear that rehabilitation of shoulder instability has a limited capacity to accommodate capsular redundancy or ligamentous laxity which results in excessive joint volume and multidirectional instability. Operative repairs are presently performed using both open techniques and arthroscopy. The open operative treatment of GHI involves procedures that historically fall into 1 of 4 groups: capsulorrhaphy, ${ }^{32,33}$ bone block procedures, ${ }^{34,35}$ subscapular muscle advancement, ${ }^{36,37}$ and osteotomies of the glenoid and humerus. ${ }^{38,39}$ The magnitude of these surgical procedures which significantly derange the local glenohumeral anatomy leads to significant morbidity. Pain, loss of motion, nerve injury, and osteoarthritis have been reported as common complications associated with these procedures. ${ }^{10}$ Recent open surgical treatments for glenohumeral instability have focused upon a more anatomic repair of the unstable shoulder, however, these procedures remain technically demanding and morbid..$^{6,8,33,40-43}$ Following these open procedures, the joint regains stability, however, shoulder stiffness continues to be a problem and less than $5 \%$ of athletes who perform activities with the arm overhead appear to be able to achieve their previous level of pre-injury function. ${ }^{6,8,33,40}$ In addition, the postoperative rehabilitation is lengthy and expensive in these patients.

Citing the obvious morbidity and complications associated with open shoulder repairs and reconstructions for GHI, numerous arthroscopic techniques have been developed as an alternative treatment. Current arthroscopic techniques include: metal staples, ${ }^{44,45}$ bioabsorbable tacks ${ }^{46}$ suture techniques, ${ }^{47,48}$ and suture anchor techniques. ${ }^{49}$ The reported benefits of arthroscopic shoulder treatments include better postoperative range of motion, less risk of neurovascular injury, and accelerated rehabilitation. However, the recurrence rate of glenohumeral instability ranges from 0 to $44 \%$ and appears to be extremely technique-dependent. ${ }^{44-48}$ Additionally, the rehabilitation needs for patients remain considerable and athletes frequently require 6 to 12 months of therapy before returning to 
their activity. The most common pathologic feature cited to contribute to residual or recurrent glenohumeral instability following arthroscopic repair is that of capsular redundancy and excessive joint volume. ${ }^{11,33,43,46,50-53}$ The technical difficulties associated with trying to arthroscopically treat multidirectional and unidirectional instability secondary to capsular redundancy has led many authors to state that arthroscopic reconstruction of this select patient population is contraindicated. ${ }^{5,6,12,43,47}$

\subsubsection{Thermal properties of collagen}

Glenohumeral joint stability is maintained by a capsulo-ligamentous complex (joint capsular tissue) that is comprised of joint capsule surrounding the shoulder joint and capsular ligaments (glenohumeral ligaments) that are thickened bundles embedded within the joint capsule. The primary function of these tissues is to limit joint translation over the normal range of motion. Joint capsular tissue (joint capsule and ligaments) is mainly composed of fibrillar collagen (type I).

Collagen, an extracellular matrix component, is the most abundant protein in the human body. Type I collagen is the main constituent of joint capsule and ligament, and these highly ordered dense collagen fibers provide these tissues with their mechanical stiffness and strength. It is a well known phenomenon that collagenous tissue shrinks when it is heated. The thermal properties of collagen have been extensively studied in a variety of experimental models in the field of physical chemistry. ${ }^{21-23,54-56}$ In the 1950s, Flory et al. described that thermal shrinkage of collagen is brought about by transition between the crystalline and amorphous phases of collagen. ${ }^{21,23} \mathrm{~A}$ number of studies have demonstrated a molecular structural transition from the triple helix to a random coil during heating; a process that is described as degradation to gelatin or as denaturation. ${ }^{20,54-56}$ More recently, shrinkage of collagen was proposed to be secondary to unwinding of the triple helix with maintenance of heat-stable intermolecular crosslinks, where each step in the unwinding process is highly sensitive to temperature. ${ }^{19}$ The thermal properties of collagen also vary with the species of the animal, the age of the animal, and the environmental condition in which the animal lives. ${ }^{26,57}$ Rosenbloom et al. reported that hydroxyproline content determines the denaturation temperature of collagen using a chick tendon model. ${ }^{57}$ Hogan et al. reported a strong correlation between the thermal properties of tendon and the concentration of non-reducible crosslinks. ${ }^{26}$ A number of different methods have been used to study this characteristic, including differential scanning calorimetry, ultraviolet difference spectroscopy, isometric tension measurement, and isotonic contraction measurement. ${ }^{19,26,54-56}$ To date, the thermal properties of collagen have been explained mainly in terms of the identity, position, and ionization state of charged residues of the amino acids of collagen and collagen's crosslinks. ${ }^{58,59}$

\subsubsection{Tissue modification using thermal effect of laser energy}

The first functional ruby laser was developed by Maiman in $1960 .^{60}$ Subsequent to the development of the ruby laser, numerous lasers in the infrared, visible-light, and ultraviolet light spectrum have been developed. When laser energy is directed at any material, the material can reflect the light, scatter it, or absorb it. The optical properties of the material govern the effectiveness of a laser by controlling the interaction between the light and the material. In biological tissues, mid-infrared and far-infrared lasers, such as the $\mathrm{CO}_{2}$ laser at $10.65 \mu \mathrm{m}$ and the Ho:YAG laser at $2.14 \mu \mathrm{m}$, are mostly absorbed by 
water. Near-infrared and visible-light lasers, such as the neodymium:YAG (Nd:YAG) laser at $1.06 \mu \mathrm{m}$ and the argon laser at $515 \mathrm{~nm}$, are absorbed relatively poorly by water but are absorbed rapidly by pigments such as hemoglobin and melanin. This optical property makes these lasers effective in the ablation of tissues which have abundant pigment, such as those in the retina, gastric mucosa, and pigmented cutaneous lesions; however, the absence of pigment in musculoskeletal connective tissues such as joint capsule, ligament, and cartilage makes these lasers less effective in most orthopedic applications. Ultraviolet-light lasers are absorbed by specific components of protein molecules, which vary with the wavelength of the laser. The absorption is due to a photochemical mechanism in which the molecular bonds of tissue proteins are broken apart.

The potential applications of laser energy in surgery and medicine have been evaluated in a variety of specialties. The interactions of laser energy and tissue are based on photothermal, photochemical, photomechanical, and photoacoustic effects. ${ }^{61,62}$ These effects are used for a wide variety of applications in medicine and surgery, including ablation or vaporization, coagulation, incisional application, interstitial hyperthermia, tissue welding, selective photothermolysis, photodynamic therapy, lithotripsy, and biostimulation. ${ }^{15,62}$ Laser applications in surgery have mainly focused on the tissue ablative action of laser energy which is primarily caused by the photothermal effect of laser energy. The nonablative application of laser energy to tissue also has been evaluated in a variety of experimental models, mainly in thermokeratoplasty, tissue welding, and skin resurfacing.

The concept of thermokeratoplasty arose from studies which demonstrated that corneal stromal collagen shrinks to approximately $1 / 3$ of its original length when heated to a temperature of 60 to $65^{\circ} \mathrm{C} .{ }^{63}$ Seiler et al. used a pulsed Ho:YAG laser to steepen corneas. ${ }^{64}$ Laser tissue welding has been evaluated in a variety of experimental models including blood vessels, skin, nerves, and bile ducts. ${ }^{65-69}$ Laser welding offers several potential advantages over conventional suture technique such as faster healing, less inflammatory response, and higher threshold for infection. ${ }^{70}$ These studies indicate that long-lasting alteration of collagenous architecture can be achieved by nonablative application of laser energy with minimal or no concomitant inflammatory response. Clinically, over the last 5-10 years, the application of controlled thermal laser energy to denature collagen and achieve a therapeutic effect has gained tremendous popularity in applications such as skin resurfacing (wrinkle ablation, or exfoliation ("peel")) thermokeratoplasty (curvature correction). ${ }^{17,64}$ Although the mechanisms behind these treatments are still being critically evaluated, clinical results generally have been excellent with ensuing tissue regeneration free of inflammation and scar formation.

\subsection{Significance}

\subsubsection{Impact of shoulder joint instability}

The magnitude of shoulder instability-related problems is reflected by the incidence of shoulder dislocation in the general population. Glenohumeral instability (GHI) affects between 2 and $8 \%$ of the population and represents $1 / 3$ of all shoulder-related emergency room visits. ${ }^{30,74,75}$ In many series, shoulder dislocations are more common than all other joint dislocations combined. ${ }^{76}$ If one considers the spectrum of shoulder instability to include transient subluxation which produces activity-related pain, then the true incidence 
of glenohumeral instability is grossly under-reported. Shoulder instability is a disease of the young and numerous studies have reported that the recurrence rate of instability is inversely proportional to the age of the patient at the time of the injury. ${ }^{77-80}$ Thus, young individuals affected by shoulder instability are afflicted by a disability that is recurring and which severely limits their capacity to work, to participate in athletics, or to perform their activities of daily living. In general, individuals with shoulder-related instability tend to decrease their level of activity to accommodate their degree of functional instability.

\subsubsection{Need for a new treatment modality}

Glenohumeral instability is a common and recurring problem that current closed, open, and arthroscopic treatments do not satisfactorily address. Closed treatment has an unacceptably high recurrence rate in the young and athletic individual. Open techniques are morbid, require prolonged rehabilitation, and return a minority of overhead athletes back to their pre-injury level of activity. Arthroscopic procedures have a higher rate of failure, require extreme technical expertise, and may be contraindicated in cases of capsular redundancy-related shoulder instability. Whether a non-operative or operative treatment is chosen, prolonged physical therapy ranging from 3 months to 12 months is routinely employed. With increasing pressures to drive down the cost of medicine, many health care plans are severely restricting either the access to physical therapy or the total number of visits available for patient treatment. Thus, considering the shortcomings of the current treatment armamentarium, there appears to be a need for a simply performed, low morbidity procedure that eliminates capsular redundancy, diminishes joint volume, and helps stabilize shoulders of patients, allowing individuals to return to their previous level of activity or performance.

\section{DEVELOPMENT OF CONCEPT AND TECHNIQUE}

The concept of thermal modification of joint capsular tissue was originated by the discovery that nonablative application of laser energy shrank joint capsular tissue. Following this initial observation, a series of in vitro and in vivo animal studies were performed to evaluate the effect of nonablative laser energy on the local and structural properties of joint capsular tissue. A human clinical trial was also initiated to evaluate the effect of laser assisted capsular shrinkage on stability of the glenohumeral joint in patients with multidirectional and unidirectional instability. Experimental studies demonstrated that nonablative laser energy produced significant tissue shrinkage that is likely caused by the thermal effect of laser energy on collagen in joint capsular tissue. The initial results of this clinical trial indicated that patients were extremely satisfied following surgery and were able to return to high-level athletic performance with minimal to no loss of shoulder function following treatment. World-class athletes in volleyball, football, baseball, and swimming who had been unable to compete, were able to return to their previous level of performance. In addition, patients who perform overhead activities in their activities of daily living, were able to return to these activities within 90 days of surgery with almost no loss of shoulder motion. Owing to the promising results of pilot experimental studies and this clinical trial, thermal modification of joint capsular tissue attracted much attention in the orthopedic society, especially in the sports medicine field. However, the validity and safety of this technique remained controversial, because the mechanism behind this effect was not fully investigated and 
there was no information regarding long term efficacy. In addition, this treatment modality did not expand partly because the Ho:YAG laser was expensive. As experimental studies indicated that the tissue modification by laser energy was predominantly caused by its thermal effect and was a function of temperature and time, new techniques utilizing another source of thermal energy, radiofrequency energy, were developed.

\subsection{Initial Discovery}

In 1993, a group of orthopedic surgeons in Utah and California observed dramatic shrinkage of joint capsular tissue when Ho:YAG laser was inadvertently applied to the joint capsule in a defocused manner. The Ho:YAG laser is an extremely useful surgical tool with its precise and powerful ablative properties. The Ho:YAG laser has many advantages for use in orthopedic and arthroscopic surgery. Ho:YAG laser energy at a wavelength of $2.1 \mu \mathrm{m}$ can be transmitted fiberoptically in a fluid environment with a low profile handpiece. Ho:YAG laser energy is highly absorbed by water, and therefore is an effective tool for most biological tissues, especially for musculoskeletal tissues. In addition, the Ho:YAG is a pulsed laser and the cooling effects between pulses in a fluid medium greatly limit the tissue damage that occurs. The Ho:YAG's low profile handpiece operates in either near-contact or contact modes and is ideal for access to tight spaces such as joints. The Ho:YAG laser has been used in many arthroscopic procedures including debridement, release, removal, resection, and excision. These applications take advantage of the Ho:YAG's excellent ablative (cutting and vaporizing) and coagulative actions. With arthroscopic application of the Ho:YAG laser, orthopedic surgeons can perform precise surgical ablation quickly without interference from bleeding.

After observing shrinkage of the joint capsule after inadvertently applying Ho:YAG laser energy in a defocused manner, a group of orthopedic surgeons hypothesized that shrinkage of joint capsular tissue by arthroscopic application of nonablative laser energy would diminish the excessively redundant joint capsular tissue in patients with glenohumeral instability, helping stabilize the joint. This new arthroscopic technique would be much less invasive than routinely performed open capsular shift procedures that involve cutting tissues and suturing them back together to shorten the joint capsular tissue to make joint tighter.

\subsection{Early Experimental Studies}

To provide fundamental information on the nonablative application of laser energy to collagenous tissues, a series of experimental studies using animal models were performed. ${ }^{81-84}$

\subsubsection{Effect of nonablative laser energy on joint capsular tissue}

Schaefer et al. (1997) reported significant shrinkage (approximately 7\%) of patellar tendon by Ho:YAG laser energy applied at 10 watts in saline solution using an in vitro rabbit model, with the mean depth of laser energy's penetration approximately $1 \mathrm{~mm}^{84}$ Hayashi et al. $(1995,1996)$ evaluated the effect of laser energy at three nonablative levels ( 5 watts $(5 \mathrm{~W}), 10$ watts $(10 \mathrm{~W})$, and 15 watts $(15 \mathrm{~W})$ ) on the mechanical, biochemical, histologic, and ultrastructural properties of joint capsular tissue in an in vitro rabbit femoropatellar joint capsular model. ${ }^{81-83}$ The application of laser energy resulted in $9 \%$, 
$26 \%$, and $36 \%$ reduction in capsular tissue length for the $5 \mathrm{~W}, 10 \mathrm{~W}$, and $15 \mathrm{~W}$ groups, respectively. Tissue shrinkage was significantly and strongly correlated with energy density ${ }^{81}$ Laser energy caused a significant decrease in the tissue's tensile stiffness in the $10 \mathrm{~W}$ and $15 \mathrm{~W}$ groups. Despite the significant decrease in the tissue stiffness, the loads required to return specimens to their original lengths were significantly higher for the $10 \mathrm{~W}$ and $15 \mathrm{~W}$ groups compared to control and $5 \mathrm{~W}$ groups. Histologic examination of the tissue revealed evidence of thermal damage of the tissue at all laser energy densities, which was characterized by hyalinization of collagen and pyknotic nuclear changes in fibroblasts. Each subsequently higher laser energy caused significantly greater morphologic changes over a larger area. ${ }^{83}$ Transmission electron microscopy revealed alteration of collagen architecture, with significantly increased fibril cross-section for each of the treated groups compared to controls. ${ }^{82}$ The fibrils began to lose their distinct edges and their periodical cross-striations at higher energy densities. Biochemical analysis indicated that application of laser energy did not cause significant alteration of collagen content and non-reducible crosslinks at any energy density. ${ }^{83}$

These studies demonstrated that significant capsular shrinkage can be achieved with the application of nonablative Ho:YAG laser energy, although at higher energy densities, laser energy did lessen capsular stiffness properties. Application of laser energy did not cause significant alteration of biochemical parameters evaluated in this study, however, histologic/ultrastructural analysis revealed significant thermal changes in the tissue.

\subsubsection{Heating musculoskeletal tissues: Temperature profile and shrinkage}

Pilot experimental studies suggested that the effect of nonablative laser energy is predominantly caused by the thermal effect of laser energy. To investigate "pure" thermal effects, several experimental studies have been performed evaluating the effect of heating on collagenous tissues. ${ }^{85-88}$ These studies have described the relationship between tissue behavior, temperature, and duration of treatment, utilizing tissue samples treated in temperature controlled tissue baths. Although the tissue response to thermal treatment (e.g., amount of tissue shrinkage) varied widely depending on the experimental conditions and therefore the results were not completely comparable, all studies demonstrated significant tissue shrinkage with heat. Wall et al. (1999) studied the effect of temperature and time on shrinkage and mechanical properties of bovine extensor tendons, reporting that tissue shrinkage was sensitive to temperature changes and mechanical properties decreased with increase shrinkage. ${ }^{88}$ Vangsness et al. (1997) reported a sharp increase in shrinkage to approximately $70 \%$ of resting length at approximately $70^{\circ} \mathrm{C}$ using fresh frozen human Achilles tendon in saline solution. ${ }^{87}$ Naseef et al. (1997) evaluated the effect of temperature and time (duration of thermal exposure) on tissue shrinkage using bovine stifle joint capsule in saline solution, and demonstrated approximately $50 \%$ shrinkage at 65,70 , and $75^{\circ} \mathrm{C}$ with thermal exposures of 1 minute or greater. ${ }^{86}$

Using human glenohumeral joint capsule/ligament specimens, Hayashi et al. (1997) evaluated the effect of temperature on shrinkage and histological properties of this tissue $^{85}$ In this study, the entire joint capsule was detached from the glenoid and humerus and seven regions of interest were collected from the superior, middle, inferior (anterior band, axillary pouch, posterior band), and posterior (inferior, superior portion) glenohumeral ligament/capsule. Specimens were treated with one of seven temperature settings $\left(37,55,60,65,70,75,80^{\circ} \mathrm{C}\right)$ under a constant load $(0.098 \mathrm{~N})$. Treatments with 
37,55 , and $60^{\circ} \mathrm{C}$ tissue baths did not cause significant changes in tissue length, whereas temperature treatments at or above $65^{\circ} \mathrm{C}$ caused significant shrinkage when compared to 37,55 , and $60^{\circ} \mathrm{C}$ groups. Post-treatment lengths in 70,75 , and $80^{\circ} \mathrm{C}$ groups were significantly less than pre-treatment lengths. Shrinkage of the tissue started immediately after the temperature treatment and reached maximum shrinkage within $3 \mathrm{~min}$ in 75 and $80^{\circ} \mathrm{C}$ groups. There was no significant effect of tissue region on tissue shrinkage. Histological analysis revealed significant thermal alteration of the tissue, characterized by hyalinization of collagen in $65,70,75$, and $80^{\circ} \mathrm{C}$ groups. These histologic properties were similar to the changes caused by nonablative energy.

These studies demonstrated that thermal heating of joint capsule, ligament, and tendon resulted in significant shrinkage that is both temperature and time dependent. ${ }^{85-88}$ The degree of tissue modification (shrinkage) is influenced by the quality of the tissue (e.g., collagen content, crosslinks) and direction of the collagen fibers. Despite the differences in experimental conditions, all these studies reported a very similar trend of tissue behavior, demonstrating $65-75^{\circ} \mathrm{C}$ as the "critical temperature range" for the thermal modification of dense collagenous tissues.

\subsubsection{Mechanism of thermal modification}

To understand the mechanism responsible for thermal modification of joint capsular tissue, Hayashi et al. (1999) evaluated the effect of nonablative laser energy on the thermal, ultrastructural, and molecular properties of femoropatellar joint capsular collagen. ${ }^{89}$ A thermometric study revealed that nonablative laser energy caused tissue temperature to rise in the range of 64 to $100^{\circ} \mathrm{C}$. Transmission electron microscopic examination showed swollen collagen fibrils, and the biochemical study revealed partial denaturation of collagen. This study support the concept that the primary mechanism responsible for the joint capsular modification is thermal denaturation of collagen in joint capsular tissue associated with unwinding of the triple helical structure of the collagen molecule.

\subsection{Pilot Clinical Trial}

As previously outlined, a multi-institutional clinical trial was undertaken evaluating the arthroscopic stabilization of shoulders in patients with multidirectional or unidirectional glenohumeral instability. ${ }^{1}$ All patients with glenohumeral instability with or without labral tears, partial thickness rotator cuff tears, or subacromial impingement not requiring acromioplasty were included in the study. Patients were excluded from the study if they had any of the following lesions associated with glenohumeral instability: capsulolabral detachment, full-thickness rotator cuff tears, or subacromial impingement syndrome resulting in acromioplasty. The laser energy ( 10 watts: $1 \mathrm{~J}, 10 \mathrm{~Hz}$ ) was radially applied to the capsule tangentially in a defocused manner, in a paint brush-like motion beginning posteroinferiorly and progressing anterosuperiorly. Treatment of the inferior, middle, and superior glenohumeral ligaments proceeded in an orderly fashion. A total of 41 shoulders in 40 patients with a mean age of 28 years (range, 15-50 years) were treated with this technique. At a mean follow-up time after surgery of 6 months (range, 2-12 months), patients were subjectively and objectively scored. For all patients, regardless of arm dominance, age, sex, or direction of instability, post-surgical subjective scores were significantly higher than pre-surgical scores. There was a significant effect of age on postoperative outcome. Although this pilot study suffered from lack of a comparable nonoperated control population or an operated open surgical repair group, these results 
indicated that at this short term follow-up, patients with glenohumeral instability without capsulolabral detachment or full-thickness rotator cuff tears improved dramatically after nonablative reduction of redundant glenohumeral joint capsule using the Ho:YAG laser.

\subsection{Development of New Technology: Radiofrequency energy}

With the promising results of several clinical trials, thermal modification of joint capsular tissue gained considerable interest among orthopedic surgeons as a new treatment technique for joint instability. However, this surgical procedure was extremely controversial because the mechanism responsible for this effect was not fully investigated and there was no information regarding long term efficacy. In addition, the use of lasers in this manner was limited by two factors: a historical bias against lasers and their cost. A series of experimental studies indicated that the tissue modification by laser energy was predominantly caused by its thermal effect not due to any intrinsic properties of lasers. A new technique utilizing radiofrequency (RF) energy was developed to deliver thermal energy to the tissue to achieve tissue shrinkage, with considerably less expense and physically smaller instrumentation compared to the Ho:YAG laser.

\subsubsection{Tissue heating by radiofrequency energy}

Radiofrequency (RF) energy is a form of electromagnetic energy that can produce controlled tissue heating through the mechanism of electrolyte oscillation and consequent molecular movement. RF generators are economic heat sources with a high degree of safety that have been used in numerous clinical applications, including cardiology, ${ }^{90}$ oncology, ${ }^{91}$ neurosurgery, ${ }^{92}$ urology, ${ }^{93}$ and thermokeratoplasty. ${ }^{94}$ In all clinical procedures, the goal of RF energy application is to produce a well-defined area of tissue heating that undergoes controlled tissue cutting with coagulation, ablation, or volume reduction. Based on the initial success of thermal modification of joint capsular tissue by laser energy (laser assisted capsular shift procedure), a RF system was developed for arthroscopic use by modifying a RF generator used for prostate ablation (Oratec Interventions, Inc, Menlo Park, CA). This monopolar RF system has several advantages over Ho:YAG laser including substantial cost benefit, ease of use, increased safety to operator, and temperature control. For thermal modification, this monopolar RF system can produce the critical temperature range $\left(65\right.$ to $\left.75^{\circ} \mathrm{C}\right)$ in joint capsular tissue. Currently, "monopolar" and "bipolor" probes are available for arthroscopic use by several manufactures. The principle of RF heating with a monopolar probe utilizes an alternating current between the application probe and the grounding plate. This ionic current density produces molecular friction in tissue which results in tissue heating. In contrast, energy produced by bipolar probe follows the path of least resistance through the conductive irrigating solution between probe tips.

\subsubsection{Effect of radiofrequency energy on joint capsular tissue}

Experimental studies were performed to evaluate whether monopolar RF energy can produce tissue heating that is required for joint capsular shrinkage and joint stabilization. Obrzut et al. (1998) evaluated the effect of monopolar RF energy on the length of glenohumeral joint capsule in an in vitro sheep study. ${ }^{95}$ Post-treatment lengths of tissues treated at $65,70,75$, and $80^{\circ} \mathrm{C}$ RF settings were significantly shorter than pre-treatment lengths. Lopez et al. $(1998,1999)$ evaluated the effect of monopolar RF energy on the mechanical, histologic, and ultrastructural properties of femoropatellar joint capsular 
tissue in an in vitro sheep study ${ }^{96,97}$ Monopolar RF treatment caused significant tissue shrinkage at 45,65 , and $85^{\circ} \mathrm{C}$ RF settings, however, tissue stiffness significantly decreased at 65 and $85^{\circ} \mathrm{C}$ RF settings. Histologic changes consisted of thermal tissue damage characterized by a fused and homogenized appearance of collagen and fibroblastic nuclear pyknosis at all application temperatures. Ultrastructural alterations included a general increase in cross-sectional fibril diameter and loss of fibril size variation with increasing treatment temperature. Biomechanical, histologic, and ultrastructural alterations by monopolar RF energy application were similar to those observed with nonablative laser energy. These studies provided basic information on temperature settings and tissue shrinkage following monopolar RF treatment, and demonstrated monopolar RF's ability to produce controlled and predictable thermal energy delivery and tissue modification.

\section{CURRENT STATUS OF THERMAL MODIFICATION OF JOINT CAPSULAR TISSUE}

As the basic scientific data were gathered in experimental studies, and as good results regarding clinical efficacy and safety spread, thermal modification of joint capsular tissue was gradually accepted as a novel treatment modality by the orthopedic community. Particularly with the development of RF systems, the use of thermal energy in arthroscopic surgery is expanding and gaining great popularity among surgeons. The surgical procedure is called the laser-assisted capsular shift (LACS) procedure, electrothermally assisted capsulorrhaphy (ETAC), or thermal capsulorrhaphy depending on the device and manufacturer. With the growth of this modality, more clinically relevant experimental studies were performed to answer the questions derived from clinical use of thermal energy. It is estimated that thermal modification of joint capsular tissue was performed in approximately 20,000 patients in 1998, and it has been predicted that this number will double in 1999. Recently, clinical results with 2-3 year follow-up have begun to be reported. To date, thermal modification of joint capsular tissue for clinical problems related to shoulder joint instability appears to be highly effective, with few major complications.

\subsection{Clinically Relevant Findings from Experimental Studies}

Previous experimental studies provided fundamental information regarding the effect of thermal modification of joint capsular tissue and the mechanism responsible for shrinkage, demonstrating significant shrinkage of the tissue with concomitant diminished tissue stiffness and thermal damage to collagen and cells. With the increased clinical use of this modality, a number of new questions were raised by surgeons. Some of these included: What were the differences between laser and RF application? How much shrinkage was needed to achieve therapeutic effects? What was the effect of this treatment on human shoulder joint stability? How long did it take to regain mechanical properties that were lost by thermal treatment? How did the thermally damaged tissue heal and what was the duration of this response? Was shrinkage maintained over time? How long should the joint be immobilized or protected? To date, there is not enough information available to answer all of these questions partly because experimental investigations have been limited due to the lack of a good animal model for human shoulder joint instability. Nevertheless, valuable information has been presented recently 
to further improve our understanding of the clinical efficacy of thermal modification of joint capsular tissue.

\subsubsection{Comparison of laser and radiofrequency energy application}

Initially, Ho:YAG laser was used for thermal modification of glenohumeral joint capsular tissue. Subsequently, RF energy was introduced clinically to achieve joint capsular shrinkage. Laser and radiofrequency treatment methods use very different methods of heating tissue. The laser achieves tissue heating based on a photothermal effect. In contrast, tissue heating by monopolar RF energy is achieved as a result of ionic agitation within the tissue because of a high frequency alternating current that flows between the probe tip and the grounding plate. Because of the different mechanisms involved, there are likely varying effects in tissue response between these two techniques, including the amount of shrinkage, depth of penetration, and the degree and distribution of thermal damage. Currently, both treatment methods have been used clinically for joint capsular shrinkage. To compare the effects of laser and RF energy, joint capsular tissues were treated with laser $\left(5,10,15 \mathrm{~W}\right.$ ) or RF energy (settings at $55,65,75^{\circ} \mathrm{C}$ ) in an in vitro ovine model ${ }^{98}$ Energy application caused significant tissue shrinkage and decreased surface area in all laser and RF treatment groups. Tissue thickness significantly increased in all treatment groups except for RF set at $55^{\circ} \mathrm{C}$. There were no significant differences among laser at $10 \mathrm{~W}$, laser at $15 \mathrm{~W}$, and $\mathrm{RF}$ set at $75^{\circ} \mathrm{C}$ treatment groups for these three architectural parameters. Despite different mechanisms, laser and RF energy can achieve similar and predictable tissue modification.

A few potential clinical advantages of using monopolar RF treatment are that the generator can be purchased for substantially less cost than a Ho:YAG laser, has less safety concerns, is physically much smaller than the laser, and has greater versatility because the application probe can be flexed. A potential disadvantage of monopolar RF energy is the inadvertent thermal modification of too much tissue at too great a depth by using a high power setting. Advantages of laser energy include the ability to ablate, coagulate, and shrink tissue with one probe by varying the distance from the probe tip to the tissue. Laser energy induces a brisk and immediate visible shrinkage of the treated tissue, whereas monopolar RF energy application results in smoother and slower shrinkage.

This study did not evaluate the effect of bipolar RF energy, an additional energy modality that is available for arthroscopic use and has been used clinically for thermal stabilization of joints. Although monopolar and bipolar RF devices use molecular friction caused by alternating current for tissue heating, the mechanism of action and resultant tissue effects by these two energy applications are completely different. Therefore, no relevant information on bipolar RF application could be deduced from this study. Bipolar RF devices heat the irrigating solution around the application probe and the tissue nearby, producing tissue effects such as shrinkage, ablation, vaporization, and cauterization. Thermal energy created by bipolar RF can shrink joint capsular tissue when the device is used at the manufacturers' recommended settings (unpublished data). However, the solution around the probe tip is intensively boiling, indicating that the temperature around the probe tip is at least $100^{\circ} \mathrm{C}$. In addition, overheating characterized by charring of the tissue is commonly observed. Therefore care must be taken when using bipolar RF for modification of tissue. To date, no peer-reviewed studies have been reported on the effect of bipolar RF energy on joint capsular tissue. 


\subsubsection{Amount of shrinkage to be achieved}

There is no information available regarding what percentage of shrinkage is therapeutic for return of normal joint stability, and this probably varies among individuals and is dependent on their abnormality. Selecky et al. (1999) and Ferrara et al. (1999) recommended $10 \%$ shrinkage because this amount of shrinkage of human glenohumeral ligament did not significantly alter failure strength. ${ }^{99,100}$ Clinically, 5 to $10 \%$ shrinkage seems to be sufficient to reduce glenohumeral translation and to regain stability (McMahon PJ, Lee TQ, personal communication) although this goal has not yet been validated experimentally. To date, there is no guideline regarding the amount of energy that should be delivered to achieve therapeutic effects in a clinical situation.

\subsubsection{Effect of thermal modification on human shoulder joint}

Previous in vitro experimental studies utilized joint capsular specimens from various animal models, which provided only limited information regarding the effect of joint capsular modification on the human shoulder joint. Selecky et al. (1999) investigated the effect of Ho:YAG laser energy on the biomechanical properties of the human inferior glenohumeral ligament complex using cadaveric shoulders. ${ }^{99}$ The shoulder capsule and its glenohumeral ligaments are significant restraints to shoulder dislocation. In particular, the inferior glenohumeral ligament complex has been shown to be the primary static restraint to anterior-inferior shoulder instability. This study demonstrated that the strength of the ligament complex was not significantly altered and the ultimate strain of the lased specimens was $23 \%$ greater than that of the nonlased specimens when tissue underwent $10 \%$ shortening with laser energy applied at 10 watts. The authors concluded that the lased specimen was able to sustain a greater amount of stretch before failure and the strength of the inferior glenohumeral ligament complex were not significantly compromised by this lasing protocol. Ferrara et al. (1999) reported a similar result using monopolar radiofrequency energy. ${ }^{100}$

Deutsch et al. (1999) studied the biomechanical effects of thermal capsulorrhaphy on resulting multidirectional translation and rotation of the human glenohumeral joint. ${ }^{101} \mathrm{RF}$ energy (set at 40 watts $/ 65^{\circ} \mathrm{C}$ ) was applied to the axillary pouch, inferior glenohumeral ligament complex, middle glenohumeral ligament, rotator interval, and posterior capsule in fresh cadaveric shoulders. The capsular shrinkage procedure resulted in reduction in joint volume (approximately 35\%) and in anterior, posterior, and inferior translation, with only a small reduction in rotation. This study demonstrated the significant effect of the capsular shrinkage technique in reducing capsular volume and multidirectional joint translation.

Tibone et al. (1998) evaluated changes in anterior and posterior glenohumeral translation after arthroscopic thermal capsulorrhaphy using nonablative laser energy in human cadaveric shoulders. ${ }^{102}$ Thermal capsulorrhaphy by Ho:YAG laser energy at 20 watts applied tangential to the anterior glenohumeral joint capsular tissue resulted in a significant reduction in anterior and posterior translation, with approximately $34 \%$ decrease in anterior translation and approximately $38 \%$ decrease in posterior translation. Similarly, another study by Tibone et al. (1998) demonstrated that thermal capsulorrhaphy using monopolar RF energy also resulted in a significant decrease in anterior and posterior translation. ${ }^{103}$ The percent reduction in translation was similar in 
both anterior and posterior directions regardless of which device was used to apply the thermal energy. These results confirm that thermal capsulorrhaphy can be used to decrease glenohumeral joint translation and may be effective for the treatment of glenohumeral instability.

\subsubsection{Biological response to thermal modification of joint capsular tissue: Healing process}

Previous in vitro studies have indicated that thermal treatment using laser or RF energy causes collagen denaturation, cell necrosis, and deleterious effects on the tissue's mechanical properties. ${ }^{81-83,89}$ Therefore, in vivo studies to investigate the tissue's biologic response to the thermal damage must be performed to verify the validity and safety of these treatments before they can be used clinically. Hayashi et al. (1999) evaluated the healing process of collagenous tissue after thermal treatment in a sheep model. ${ }^{104}$ Femoropatellar joint capsule was treated with either laser energy or RF energy under arthroscopic guidance and treated joint capsular specimens were harvested at $0,1,2,4,8$, 12 , and 24 weeks after surgery. Stiffness of laser treated tissue at 0 and 1 week after surgery was significantly lower than control, however at 2 weeks and beyond, stiffness were not significantly different from control. Failure strength tended to be lower than the control at 1 and 2 weeks after laser treatment. RF energy caused a significant decrease in tissue stiffness at 0 and 2 weeks after surgery. Failure strength had a trend to be lower than the control at 2 weeks after radiofrequency treatment.

Histology following both treatment modalities demonstrated immediate collagen hyalinization and cell necrosis, followed by an active cellular reparative response characterized by extensive fibroblast migration and capillary sprouting, and subsequent tissue maturation. Histologic examination of treated samples at time 0 revealed hyalinization of collagen with nuclear karyorrhexis of fibroblasts following both laser and RF energy application. In the laser treated tissue, histologic alterations were limited to the directly treated regions, whereas RF treated tissue demonstrated a more uniform thermal effect throughout the joint capsular tissue. For both laser and RF groups, reactive fibroblasts and vascular responses were significantly increased around the treated region at 2 weeks after surgery. Interestingly, subcapsular muscle necrosis caused by the thermal effect of RF energy at high power settings induced a severe inflammatory response, whereas inflammation was not evident in ligamentous regions of the capsule. Hyalinized regions were gradually reduced and replaced with cellular fibrous tissue at 4 weeks after laser treatment and at 6 weeks after RF treatment. Although cellularity remained elevated in both laser and RF treated tissue, joint capsular tissue regained its organized fibrous appearance at 12 weeks after surgery. Transmission electron microscopy revealed that the treated region was infiltrated with fibroblasts and replaced with fine collagen fibrils by 12 weeks post surgery. Tissue culture studies demonstrated that collagen synthetic activity of laser treated tissue was $64 \%$ of control at day 0 , however collagen synthesis increased significantly at 1 week (196\%) and 2 weeks (197\%) after treatment. The biochemical analysis of collagen revealed that thermal treatment initially caused denaturation of joint capsular collagen, which over time then regained its native structure.

This study illustrated an active and prompt tissue response to the tissue modification, with concomitant improvement of mechanical properties by 6 weeks after surgery. Treatment by laser and RF energy induced similar cellular responses after thermal 
modification of joint capsular tissue. This study revealed that thermally modified joint capsular tissue was actively repaired and returned to pre-treatment mechanical properties by 6 weeks after surgery, although histologic return to normalcy required 12-24 weeks and the treated tissue had not returned to a completely normal ultrastructural appearance at 6 months after treatment. Thermal treatment did cause cell necrosis, collagen denaturation, and an initial deleterious effect on mechanical properties, therefore the joint should be protected during this healing phase by limiting motion for 6 to 12 weeks after surgery.

\subsubsection{Maintenance of shrinkage over time and effect of joint immobilization}

The in vivo study by Hayashi et al. described above (3.1.4) did not examine whether significant shrinkage was maintained over time in vivo. Schaefer et al. (1997) showed in a rabbit patellar tendon model that despite significant immediate shrinkage after laser application, the patellar tendon stretched out within 4 weeks after surgery when subjected to immediate physiological loading after surgery. ${ }^{84}$ This study demonstrated that significant tendon shrinkage (6.6\%) occurred after Ho:YAG laser energy application (10 $\mathrm{W})$, however, tendon length increased significantly beyond the immediate postlaser length at 4 weeks and beyond its original length by 8 weeks after surgery. At 8 weeks, the lased tendons were significantly less stiff with significantly greater cross-sectional areas than contralateral controls. The authors concluded that after initial shrinkage, lasermodified tissues demonstrate a loss of tensile stiffness and can stretch out to beyond preshrinkage length when exposed to normal physiologic load. Using the identical animal model, Schlegel (1999) evaluated the effect of postoperative immobilization on the healing of thermally modified tissue using monopolar RF. ${ }^{105}$ Rabbit patellar tendon was treated with monopolar RF energy and the limb was either not immobilized, immobilized for 2 weeks, or immobilized for 4 weeks (8 week survival time for all animals). Immobilization for 4 weeks resulted in a significant decrease in tissue elongation when compared to non-immobilized and 2 week immobilized groups at 8 weeks. All treatment groups demonstrated a significant decrease in tissue tensile stiffness when compared to normal controls. The authors concluded that early activity can lead to stretching of the thermally shortened tissue and postoperative immobilization is important following thermal modification of joint capsular tissue.

Wallace et al. (1999) reported that shrinkage induced by RF energy was maintained for 12 weeks using a rabbit medial collateral ligament model. ${ }^{106}$ In this study, abnormal laxity was experimentally created by elevating and shifting the tibial insertion of the medial collateral ligament. Monopolar RF energy was applied to the midsubstance of the shifted ligament. Laxity of the ligament was significantly reduced with thermal treatment at time 0 , with stability maintained for up to 12 weeks after surgery. However, the tissue's viscoelastic properties (creep behavior) were significantly altered by thermal modification of the ligament. This study indicated that although laxity may be reduced, there is a potential risk of recurrent elongation during early loading of the tissue.

\subsubsection{Potential mechanisms of postoperative joint stabilization}

Studies have demonstrated that thermal energy can be used to produce controlled tissue modification such as shrinkage, and both laser and RF energy can create predictable thermal effects in the tissue. Despite the immediate thermal damage to the tissue, thermal modification of joint capsular tissue does not lead to permanent tissue injury, as a 
residual population of fibroblasts repairs the tissue by replacing denatured collagen with new collagen. A critical aspect of this treatment is that the application of thermal energy to achieve joint stability relies on both an initial effect (shrinkage) and the tissue's healing response to regain the tissue's mechanical properties while maintaining its shorter length. It is also possible that shrinkage alone is not the reason for clinical effectiveness of thermal treatment. Schaefer et al. (1997) demonstrated increased cross-sectional area in healing tendon after laser thermal modification. ${ }^{84}$ Wallace et al. (1999) also reported increased cross-sectional area in healing ligament after monopolar RF thermal modification. ${ }^{106}$ Hayashi et al. (1999) described an active healing process of joint capsular tissue following laser and monopolar RF thermal modification, which is characterized by repair of the thermally treated tissue with thicker fibrous tissue. ${ }^{104}$ Therefore, we believe that induction of active repair (fibrosis) and joint capsular thickening, concomitant with tissue remodeling and maturation regulated by functional demand are essential factors for successful outcome of thermal modification of joint capsular tissue. Arnoczky (1999) proposed the following mechanisms as the reasons for clinical effectiveness of the thermal joint stabilization: (1) initial shrinkage, (2) secondary cicatrix formation and collagen deposition, and/or (3) thermal denervation in joint capsular tissue. ${ }^{107}$

\subsection{Early Clinical Results}

Although there have been no clinical study reported in peer-reviewed journals, early clinical results with 2-3 year follow up have recently been reported. To date, thermal modification of joint capsular tissue for shoulder joint instability is generally effective with no major complications.

\subsubsection{Histologic evaluation of glenohumeral joint capsular tissue after thermal modification}

Hayashi et al. (1999) evaluated histologic properties of glenohumeral joint capsular tissues obtained from 42 patients who had undergone an arthroscopic laser-assisted capsular shift (LACS) procedure. ${ }^{108}$ A total of 53 samples from the anterior inferior glenohumeral ligament of the joint capsule were collected before and at various times after the LACS procedure (range, time 0 to 38 months post-surgery). Despite glenohumeral instability, joint capsule of the patients before LACS showed no significant histologic lesions. Laser treatment significantly altered histologic properties of the tissue characterized by hyalinization of collagen and necrotic cells (time 0 ). Tissues sampled during 3-6 months after the surgery demonstrated fibrous connective tissue with reactive cells and vasculature. Collagen and cell morphology returned to normal in the postoperative period between 7 to 38 months, while the number of fibroblasts remained elevated. Six patients experienced mild stiffness after the LACS procedure. Joint capsule collected from these shoulders showed persistent synovial, cellular, and vascular reaction even after one year post-operatively. This study revealed histologic evidence of robust tissue healing and maturation after thermal treatment by the LACS procedure. The incidence of arthrofibrosis (stiff shoulder) following the LACS procedure is estimated to be less than $1 \%$ of all LACS-treated patients and these patients improved after therapeutic manipulation, however, the cause of arthrofibrosis in these patients is unclear. This result indicated that further follow-up studies in this area are needed. 


\subsubsection{Clinical results of laser and monopolar radiofrequency thermal capsulorrhaphy}

Frogameni et al. (1999) reported the clinical outcome of laser-assisted capsular shift (LACS) procedure for symptomatic multidirectional glenohumeral instability in 41 patients with a minimum of two year follow up. ${ }^{109}$ The LACS procedure was performed using a Ho:YAG laser set at 10 watts applied to the inferior glenohumeral complex and advanced anteriorly or posterioirly depending on the pathology. All patients were followed for a minimum of two years and underwent a subjective and objective examination. Overall, $84 \%$ of the shoulders had a satisfactory outcome. Six patients who demonstrated primary posterior, inferior multidirectional instability had only $50 \%$ success. Five of the 41 patients experienced recurrent episodes of instability. Savoie $e t$ al. (1999) reported the result of the LACS procedure for symptomatic multidirectional shoulder instability in 33 patients with mean of 25.5 months. ${ }^{110}$ Only 1 of the 33 patients had recurrent instability after the LACS procedure. The author concluded that the LACS procedure is superior to arthroscopic capsular shift.

Fanton (1999) reported clinical results of thermal capsulorrhaphy using monopolar RF energy in 54 patients. ${ }^{111}$ At 2 years follow up, the success rate was over $90 \%$ (with good or excellent results). All patients maintained excellent post-operative range of motion. Five of the 54 patients demonstrated fair or poor results, which the author concluded were due to insufficient joint protection or other pathology such as a large Hill-Sachs lesion that should be considered a contraindication to arthroscopic stabilization. There have been 2 complications in this 54 patient population. One patient developed adhesive capsulitis that required prolonged physical therapy to regain range of motion, and at 26 months post-operatively the patient was fully active with no residual pain or instability. One patient developed a temporary sensory axillary neuritis post-operatively, although symptoms completely resolved at 4 weeks and the patient had an excellent result at 2 years after surgery.

Andrews (1999) reported short term results of thermal capsular shrinkage using monopolar RF energy in 46 throwing athletes, with excellent rates of return to competition and excellent subjective post-operative scores, and very low incidence of complications. ${ }^{112}$ The author stated that SLAP legions signify more severe shoulder pathology and decrease the odds of return to the same level of competition regardless of treatment method. D'Alessandro (1999) reported improvement of shoulder score from 43 to 87 after monopolar RF thermal capsulorrhaphy in 33 shoulder with multidirectional glenohumeral instability. ${ }^{113}$ Warren (1999) reported combined result of thermal capsulorrhaphy by laser and monoploar RF energy in 68 patients with dislocation, subluxation, or multidirectional instability, with improvement of shoulder scores from 40 to 80 postoperatively. ${ }^{114}$

These early clinical results have demonstrated clinical efficacy of thermal modification of joint capsular tissue as a treatment for shoulder joint instability and related clinical problems at approximately 2 years follow up. Complications were infrequent and minor. Sensory axillary neuritis was observed as a postoperative complication, which was mild and temporary. Postoperative shoulder stiffness (feeling tight) may be due to overtreatment or idiopathic hyperreaction of the tissue. Post-operative insufficient stabilization may be due to under-treatment or pre-existed pathology such as abnormal collagen. Non-responsiveness to thermal treatment was probably due to pathology other 
than capsular redundancy. Fanton (1999) stated that patients with multidirectional instability seem to be more resistant to thermal treatment compared to patients with unidirectional instability. ${ }^{111}$ Warren had an impression that thermal capsulorrhaphy by laser caused more stiff shoulders compared to monopolar RF energy. Although there is no formal guideline for post-operative care, it is generally recommended that the joint be immobilized for 2 to 3 weeks before physical therapy is initiated. At 5 to 6 weeks strengthening and endurance exercise are permitted within the limited range of motion, and sports activity may be started at 12 weeks post-operatively. All authors stated that careful patient selection and postoperative rehabilitation protocols are essential for the successful outcome of thermal capsulorrhaphy.

\section{FUTURE DIRECTIONS}

Thermal modification of joint capsular tissue has become accepted as a novel treatment modality for joint instability among orthopedic surgeons. With this initial clinical success, applications of this principle in other musculoskeletal collagenous tissues have been initiated, extending beyond the shoulder to other debilitating conditions such as anterior-posterior knee instability and patellar instability. In addition, thermal modification has the potential to be expanded to other collagenous tissues such as cartilage. As previous experimental studies and pilot clinical trails have demonstrated, thermal modification of musculoskeletal collagenous tissues may become an important modality in the treatment of joint disorders in the future.

\subsection{Applications to Other Joint Instabilities}

Thabit (1998) reported a technique utilizing the thermal effect of monopolar RF energy for treatment of chronic anterior cruciate ligament (ACL) instability. ${ }^{15}$ Injury to the $\mathrm{ACL}$ is common and involves one of four mechanisms: bony avulsion, midsubstance disruption, proximal or distal ligamentous avulsion, and interstitial ligamentous disruption and attenuation. The surgical options for these problems vary depending on the type of pathology present. Ligamentous disruption and avulsion may be primarily repaired or secondarily reconstructed. Chronic ACL insufficiency secondary to interstitial ligamentous disruption is usually managed by reconstruction. Reconstructive methods include the use of autogenous or allogeneic tissue, as bone-patellar tendon-bone, hamstring, achilles, or quadriceps grafts. ACL reconstruction is recognized as the treatment of choice for ACL injuries because of its predictable results and ease of rehabilitation, however, these procedures are associated with a variety of post-operative complications including recurrence of instability due to interstitial ligamentous creep or disruption. It was therefore hypothesized that laxity secondary to graft creep after reconstructive surgery can be corrected by thermally treating the grafted tissue. Thabit (1998) described arthroscopic thermal tightening of reconstructed ACL using monopolar RF energy with resultant immediate postoperative stability of the knee joint. Rehabilitation protocols and long term results remain to be evaluated.

Dillingham (1998) reported medial stabilization of the patella utilizing monopolar RF energy. ${ }^{116}$ Recurrent patellar instability is a frequent cause of knee disability. In this joint disorder, chronic interstitial medial retinacular and patellofemoral ligamentous deformation occurs. To rebalance the parapatellar soft tissues as a treatment for patellar instability, medial retinacular soft tissues must be realigned in conjunction with release of the lateral retinacular restraints. The standard procedures involve tightening of the 
medial retinaculum and patellofemoral ligament by surgical sutures and imbrication. It was therefore hypothesized that arthroscopic application of monopolar RF energy may allow medial retinacular tightening through RF energy's thermal effect. Dillingham (1998) reported intraoperative tightening and thickening of the medial retinaculum resulting in immediate improvement of patellar instability following medial retinacular thermal capsulorrhaphy and lateral retinacular release using monopolar RF. A pilot study has revealed uniformly successful treatment of all cases, with improvement in patellar tilt and medial translation, with no recurrence of patellar dislocation.

In addition to the shoulder and knee joints, successful application of thermal modification to other tissues to treat various joint instabilities has been reported. Monopolar RF energy has been used to reduce the redundant posterior joint capsule of unstable hip joints, with dramatic clinical success at short term follow up. Shrinkage and tightening of ligamentous tissues have been reported following monopolar RF energy application to the anterior talofibular ligament for ankle instability and posterior cruciate ligament for knee instability. Although these reports are not controlled and critically reviewed, clinical outcomes have been highly successful thus far. This method of joint instability treatment is favored by many orthopedic surgeons because of its minimal invasiveness, its immediate visual stabilizing effect, its ease of use, its cost and time effectiveness, and its ability to access tight joint spaces. In addition, arthroscopic application of this technique does not eliminate the possibility of further aggressive surgery. The use of thermal energy to modify musculoskeletal collagenous soft tissues (joint capsule, ligament, tendon, retinaculum) is expanding and has the potential to become a prominent treatment modality for joint instability in the future.

\subsection{The Use of Radiofrequency Energy for Cartilage}

Applications of thermal energy to musculoskeletal collagenous soft tissues (joint capsule, ligament) have been generally successful with ensuing tissue repair and remodeling. Cartilage (articular cartilage) is an essential joint structure composed of a specialized extracellular matrix (collagens and proteoglycans), cells (chondrocytes), and water, which demonstrates unique biological properties distinct from other collagenous soft tissues. Because of the limited ability of articular cartilage to repair itself, numerous techniques including joint lavage, partial and full thickness debridement, micropicking, osteochondral auto- and allografting, mosaicplasty, and in severe cases, partial and total joint arthroplasty have been investigated for reestablishing normal joint function following cartilage injury and osteoarthritis. Monopolar and bipolar RF energy have become frequently used arthroscopic techniques for the thermal modification of intraarticular soft tissue structures in orthopedic surgery. Recently, many orthopedic surgeons in the field of sports medicine are actively using RF energy to modify the articular surfaces of damaged cartilage during the arthroscopic examination of abnormal joints. Although the effects of RF energy on the peri-articular soft tissue structures have been investigated, the effect of RF energy on articular cartilage has not been determined. While anecdotal reports and second look arthroscopies indicate that patients are clinically improved following radiofrequency treatment of the articular cartilage surface, the long term objective assessment of cartilage modification by RF energy has not been determined. Preliminary research indicates that RF energy used at the current manufacturers' recommendations with room temperature lavage solution produces successful thermal sealing of the articular surface of cartilage based on scanning electron microscopy but results in partial to full thickness chondrocyte death. Because of these 
findings, current research is focused on measures to reduce the depth of chondrocyte death induced while allowing the thermal modification of the articular surface in a timely manner.

\subsection{Improvements to the Device}

Currently, the use of laser energy for thermal application is declining as RF systems have developed. Extensive research efforts have mainly focused on the techniques utilizing the monopolar RF system. Modifications to the monopolar RF device may include improvements to the generator and probe. With regard to the generator, designing software that can accurately monitor probe temperature and respond rapidly enough to prevent temperature oscillation and therefore limit the variability of the treated tissue response would be ideal. Probe design should address several issues. A malleable probe that can be used arthroscopically is required. The malleable probe will allow the surgeon to modify the shape intraoperatively and therefore result in the need for fewer probes for each patient. The optimal probe size and shape for capsulorrhaphy and chondroplasty, and the effect of probe size and shape on treatment area in musculoskeletal tissues has yet to be determined. The probe tip should be made of a resilient material that provides rapid heat conduction so that tissue temperatures can be monitored accurately, and the thermocouple must be oriented to accurately reflect the treated tissue temperature with minimal influence from non-treated tissues and lavage fluids. The probes should be insulated to reduce environmental influences (lavage fluid temperature and flow), but it may be ideal if a thermal insulator were available that extended to the treatment surface that allowed ionic conductance over a larger region. With this development, lavage temperature would have less effect on probe tip temperature due to increased thermal insulation but the electromagnetic pathway would not be reduced due to increased surface area of the probe tip. Development and improvement of the technology is actively being investigated based on the clinical demand and surgeon's feedback.

\subsection{Clinical Concerns with Thermal Modification of Musculoskeletal Collagenous Tissues and Its Future}

Over the past several years, thermal modification of joint capsular tissue with arthroscopic application of laser and monoploar RF energy has gained popularity for the reduction of joint capsular volume as a treatment for shoulder instability. Warner (1999) summarized current clinical concerns with this new treatment modality. ${ }^{117}$ Although this technique is attractive based on its minimum invasiveness which can be performed quickly in an outpatient surgical setting, clinical experience has been primarily uncontrolled, retrospective, and anecdotal. While initial successes are encouraging, the ultimate risks and benefits remain unclear. Formal open capsulorrhaphy techniques are proven and reliable in treatment of capsular laxity which contributes to joint instability. Nevertheless, arthroscopic thermal capsular modification appears to be a safe, minimally invasive, and minimally morbid alternative. Warner (1999) emphasized that future carefully conceived and executed prospective studies will be necessary to validate this method of treatment and define the relative risks of the procedure. 


\section{ACKNOWLEDGEMENTS}

The authors wish to express special thanks to Dr. Ryland Edwards III, John J. Bogdanske, and Jennifer J. Devitt. The authors thank Drs. Steven P. Arnoczky, A. James Cooley, Michael F. Dillingham, Gary S. Fanton, Paul Hecht, Mandi J. Lopez, Yan Lu, John F. Orwin, George Thabit III, and Ray Vanderby Jr.

\section{REFERENCES}

1. G. Thabit III, "The arthroscopically assisted holmium:YAG laser surgery in the shoulder," Operative Techniques in Sports Medicine, D. Drez and J. C. DeLee, 6, pp. 131-138, W.B. Saunders Company, Philadelphia, 1998.

2. M. P. Banas, P.G. Dalldorf, K. E. DeHaven, "The Allman modification of the Bristow procedure for recurrent anterior glenohumeral instability," Sports Med. Arthroscopy Rev. 1, pp. 242-248, 1993.

3. J. J. Brems, J. Bergfeld, "Multidirectional shoulder instability," Orthop. Trans. 15, pp. 84, 1991.

4. R. J. Emery, A. B. Mullaji, "Glenohumeral joint instability in normal adolescents: Incidence and significance," J. Bone Joint Surg. 73B, pp. 406-411, 1991.

5. R. G. Pollock, L. U. Bigliani, "Glenohumeral instability: Evaluation and treatment," J. Am. Acad. Ortho. Surg. 1, pp. 24-32, 1993.

6. D. W. Altchek, R. F. Warren, M. J. Skyhar, "T-plasty modification of the Bankart procedure for multidirectional instability of the anterior and inferior types," J. Bone Joint Surg. 73A, pp. 105-112, 1991.

7. W. Z. Burkhead, C. A. Rockwood, "Treatment of instability of the shoulder with an exercise program," J. Bone Joint Surg. 74A, pp. 890-896, 1992.

8. F. W. Jobe, C. E. Giangarra, R. S. Kvitne, "Anterior capsulolabral reconstruction of the shoulder of athletes in overhand sports," Am. J. Sports Med. 19, pp. 428-434, 1991.

9. R. D. Lebar, A. H. Alexander, "Multidirection shoulder instability. Clinical results of inferior capsular shift in the active-duty population," Am. J. Sports Med. 20, pp. 193-198, 1992.

10. J. P. Warner, P. H. Marks, "Management of complications of surgery for anterior shoulder instability," Sports Med. Arthroscopy Rev. 1, pp. 272-292, 1993.

11. D. C. Young, C. A. Rockwood, "Complications of failed Bristow procedure and their management," J. Bone Joint Surg. 73A, pp. 969-981, 1991.

12. M. J. Pagnani, R. F. Warren, "Multidirectional instability: Medial T-plasty and selective capsular repairs," Sports Med. Arthroscopy Rev. 1, pp. 249-258, 1993.

13. R. G. Pollock, E. L. Flatow, "The efficacy of physical therapy for the shoulder," The Shoulder: A Balance of Mobility and Stability, F. A. Matsen, F. H. Fu, R. J. Hawkins, pp. 401-413, American Academy of Orthopaedic Surgeons, Rosemont, IL, 1993.

14. B. Zarins, "Anterior shoulder stabilization using the Bankart procedure," Sports Med. Arthroscopy Rev. 1, pp. 259-265, 1993.

15. H. H. Sherk, "The use of lasers in orthopaedic procedures," J. Bone Joint Surg. 75A, pp. 768-776, 1993.

16. C. R. Guthrie, L. W. Murray, G. E. Kopchok, "Biochemical mechanisms of laser vascular tissue fusion," J. Invest. Surg. 4, pp. 3-12, 1991. 
17. H. Moreira, M. Campos, M. R. Sawusch, "Holmium laser thermokeratoplasty," Ophthalmology. 100, pp. 752-761, 1993.

18. V. M. Thompson, T. Seiler, D. S. Durrie, T. B. Cavanauph, "Holmium:YAG laser thermokeratoplasty for hyperopia and astigmatism: An overview," Refract. Corneal Surg. 9, pp. 134-137, 1993.

19. J. C. Allain, M. Le Lous, L. Cohen-Solal, S. Bazin, "Isometric tension developed during the thermal swelling of rat skin," Conn. Tiss. Res. 7, pp. 127$133,1980$.

20. A. Finch, D. A. Ledward DA, "Shrinkage of collagen fibres: A differential scanning calorimetric study," Biochim. Biophys. Acta. 278, pp. 433-439, 1972.

21. P. J. Flory, R. R. Garrett, "Phase transition in collagen and gelatin systems," $J$. Am. Chem. Soc. 80, pp. 4836-4845, 1958.

22. P. J. Flory, O. K. Spurr, "Melting equilibrium for collagen fibers under stress. Elasticity in the amorphous state," J. Am. Chem. Soc. 83, pp. 1308-1316, 1960.

23. P. J. Flory, E. S. Weaver, "Helix coil transition in dilute aqueous collagen solutions," J. Am. Chem. Soc. 82, pp. 4518-4525, 1959.

24. W. Gorisch, K. P. Boergen, "Heat-induced contraction of blood vessels," Lasers Surg. Med. 2, pp. 1-13, 1982.

25. A. R. Haly, J. W. Snaith, "Calorimetry of rat tail tendon collagen before and after denaturation: The heat of fusion of its absorbes water," Biopolymers. 10, pp. 1681-1699, 1971.

26. D. J. Hogan, N. L. King, L. B. Kurth, "Collagen crosslinks and their relationships to the thermal properties of calf tendons," Arch. Biochem. Biophys. 281, pp. 21-26, 1990.

27. A. R. Karduna, G. R. Williams, J. L. Williams, J. P. Iannotti, "Kinematics of the glenohumeral joint: Influences of muscle forces, ligamentous constraints, and articular geometry," J. Orthop. Res. 14, pp. 986-993, 1996.

28. N. E. Pratt, "Anatomy and biomechanics of the shoulder," J. Hand Therapie. 7, pp. 65-76, 1994.

29. K. P. Speer, "Anatomy and pathomechanis of shoulder joint," Clin. Sports Med. 14, pp. 751-760, 1995.

30. L. Hovelius, "Anterior dislocation of the shoulder in teenagers and young adults," J. Bone Joint Surg. 69A, pp. 393-399, 1987.

31. D.W. Altchek, "Shoulder instability in the throwing athlete," Sports Med. Arthroscopy Rev. 1, pp. 210-216, 1993.

32. M. J. Pagnani, R. F. Warren, "Multidirectional instability: Medial T-plasty and selective capsular repairs," Sports Med. Arthroscopy Rev. 1, pp. 249-258, 1993.

33. C. R. Rowe, D. Patel, W. W. Southmayd, "The Bankart procedure: A long-term end-result study. J. Bone Joint Surg. 60A, pp. 1-16, 1978.

34. A. J. Helfet, "Coracoid transplantation for recurring dislocation of the shoulder," J. Bone Joint Surg. 40B, pp. 198-202, 1958.

35. S. Hybbinette, "De la transplantation d'um fragment osseux pour remedier aux luxations recidivantes de l'epaule: Constatations et resultats operatoires," Acta. Chir. Scand. 71, pp. 411-443, 1932.

36. H. O. Clarke, "Habitual dislocation of the shoulder: The Putti-Platt operation," J. Bone Joint Surg. 30B, pp. 19-25, 1948.

37. P. B. Magnuson, J. K. Stack, "Recurrent dislocations of the shoulder," J. A. M. A. 123, pp. 889-892, 1943.

38. A. K. Saha, Theory of Shoulder Mechanism: Descriptive and Applied, Charles C. Thomas, Springfield, IL, 1961. 
39. B. G. Weber, "Operative treatment for recurrent dislocation of the shoulder," Injury. 1, pp. 107-109, 1969.

40. L. U. Bigliani, P. R. Kurzweil, C. C. Schwartzbach, E. L. Flatow, I. Wolfe, "Inferior capsular shift procedure for anterior/inferior shoulder instability in athletes," Orthop. Trans. 13, pp. 560, 1989.

41. C. S. Neer II, T. E. Fithian, P. E. Hansen, "Reinforced cruciate repair for anterior dislocation of the shoulder,' Orthop. Trans. 9, pp. 44-45, 1985.

42. C. S. Neer II, C. R. Foster, "Inferior capsular shift for involuntary inferior and multidirectional instability of the shoulder: A preliminary report,' J. Bone Joint Surg. 62A:897-908, 1980.

43. S. C. Thomas, F. A. Matsen III, "An approach to the repair of avulsion of the glenohumeral ligaments in the management of traumatic anterior glenohumeral instability," J. Bone Joint Surg. 71A, pp. 506-513, 1989.

44. L. L. Johnson. "Arthroscopic management for shoulder instability: Stapling," the Arthroscopic Association of North America 1998, Atlanta, GA, 1988.

45. L. S. Matthews, W. L. Vetter, S. J. Oweida, J. Spearman, D. L. Helfet, "Arthroscopic staple capsulorrhaphy for recurrent anterior shoulder instability," Arthroscopy. 4, pp.106-111, 1988.

46. D. W. Altchek, "Shoulder instability in the throwing athlete," Sports Med. Arthroscopy Rev. 1, pp. 210-216, 1993.

47. R. B. Caspari, F. H. Savoie, "Arthroscopic reconstruction of the shoulder: the Bankart repair," Operative Arthroscopy, J. B. McGinty, pp. 507-515, Raven Press, New York, 1991.

48. C. D. Morgan, A. B. Bodenstab, "Arthroscopic Bankart suture repair: technique and early results," Arthroscopy. 3, pp. 111-122, 1987.

49. E. Wolf, R. Wilk, J. Richmond, "Arthroscopic Bankart repair using suture anchors,' Tech. Orthop. 1:184, 1991.

50. C. R. Foster, "Multidirectional instability of the shoulder in the athlete," Clin. Sports Med. 2, pp. 355-367, 1983.

51. R. H. Hawkins, R. J. Hawkins, "Failed anterior reconstruction for shoulder instability," J. Bone Joint Surg. 67B, pp. 709-714, 1985.

52. F. A. Matsen III, J. D. Zuckerman, "Anterior glenohumeral instability," Clin. Sports Med. 2, pp. 379-348, 1983.

53. R. R. Protzman, "Anterior instability of the shoulder," J. Bone Joint Surg. 62A, pp. $909-918,1980$.

54. C.C Danielsen, "Precision method to determine temperature of collagen using ultraviolet difference spectroscopy," Collagen Rel. Res. 2, pp. 143-150, 1982.

55. P. Kronick,B. Maleeff, R. Carroll, "The locations of collagen with different thermal stabilities in fibrils of bovine reticular dermis," Conn. Tiss. Res. 18, pp. 123-134, 1988.

56. F. Verzar, I. Zs-Nagy, "Electronmicroscopic analysis of thermal collagen denaturation in rat tail tendons," Gerontologia. 16, pp. 77-82, 1970.

57. J. Rosenbloom, M. Harsch, S. Jimenez, "Hydroxproline content determines the denaturation temperature of chick tendon collagen," Arch. Biochem. Biophys. 158, pp. 478-484, 1973.

58. V. C. Chan, J. A. Ramshaw, A. Kirkpatric, K. Beck, B. Brodsky, "Positional preferences of ionizable residues in Gly-X-Y triplets of the collagen triplehelix," J. Biol. Chem. 272, pp. 3144 1-6, 1997.

59. S. K. Holmgren, K. M. Taylor, L. E. Bretsher, R. T. Raines, "Code for collagen's stability deciphered," Nature. 392, pp. 666, 1998. 
60. T. H. Maiman, "Stimulated optical radiation in ruby. Nature. 187:493-494, 1960.

61. G. L. LeCarpentier, M. Motamedi, L. P. Mcmath, "Continuous wave laser ablation of tissue: Analysis of thermal and mechanical events," IEEE Trans. Biomed. Eng. 40, pp. 188-200, 1993.

62. S. J. O'Brien, D. V. Miller, "The contact neodymium-yttrium aluminum garnet laser," Clin. Orthop. Rel. Res. 252, pp. 95-100, 1990.

63. E. L. Shaw, A. R. Gasset, "Thermokeratoplasty (TKP) temperature profile. Invest. Ophthalmol. 13, pp. 181-186, 1974.

64. T. Seiler, M. Matallana, T. Bende, "Laser thermokeratoplasty by means of a pulsed holmium:YAG laser for hyperopic correction," Refract. Corneal. Surg. 6, pp. 355-359, 1990.

65. L. S. Bass, N. Moazami, J. Pocsidio, "Changes in type I collagen following laser welding," Lasers Surg. Med. 12, pp. 500-505, 1992.

66. E. R. Campion, D. K. Bynum, S. K. Powers, "Repair of peripheral nerves with the argon laser. A functional and histological evaluation," J. Bone Joint Surg. 72A, pp. 715-723, 1990.

67. J. A. Pearce, S. Thomsen, "Kinetic models of laser-tissue fusion processes," Biomed. Sci. Instrum. 29, pp. 355-360, 1993.

68. R. Schober, F. Ulrich, T. Sander, H. Dürselen, S. Hassel, "Laser-induced alteration of collagen substructure allows microsurgical welding," Science. 232, pp. 1421-1422, 1983.

69. R. A. White, G. E. Kopchok, G. H. White, S. R. Klein, J. Uitto, "Laser vascular anastomotic welding," Lasers in Cardiovascular Disease, R. A. White RA and W. S. Grundfest, pp. 103-117, Year Book Medical Publishers, Chicago, 1987.

70. M. Y. Rabau, I. Wasserman, S. Shoshan, "Healing process of laser-welded intestinal anastomosis," Lasers Surg. Med. 14, pp. 13-17, 1994.

71. T. S. Alster, M. S. Bettencourt, Review of cutaneous lasers and their applications," South. Med. J. 91, pp. 806-14, 1998.

72. W. G. Chernoff, H. Cramer, "Rejuvenation of the skin surface: laser exfoliation," Facial Plast. Surg. 12, pp. 135-45, 1996

73. L. David, J. Ruiz-Esparza, "Fast healing after laser skin resurfacing," Dermat. Surg. 23, pp. 359-361, 1997

74. R. H. Cofield, B. F. Kavanagh, F. J. Frassica, "Anterior shoulder instability," AAOS Instructional Course Lectures 34, pp. 210-217, CV Mosby, St. Louis, MO, 1985.

75. C. R. Rowe, H. T. Sakellarides, "Factors related to recurrences of anterior dislocation of the shoulder," Clin. Orthop. 20, pp. 40-48, 1961.

76. A. Thorndike, Athletic Injuries, Lea \& Febiger, Philadelphia, 1956.

77. J. H. Henry, J. A. Geriung, "Natural history of glenohumeral dislocation, revisited," Am. J. Sports Med. 10, pp. 135-137, 1982.

78. H. L. McLaughlin, W. W. Cavallaro, "Primary anterior dislocation of the shoulder," Am. J. Surg. 80, pp. 615, 1950.

79. W. T. Simonet, R.H. Cofield, "Prognosis in anterior shoulder dislocation," Am. J. Sports Med. 12, pp. 19-24, 1984.

80. C.R. Rowe, "Dislocations of the shoulder," The Shoulder, C. R. Row, pp. 165, Churchill Livingston, New York, 1988.

81. K. Hayashi, M. D. Markel, G. Thabit III, J. J. Bogdanske, R. Thielke, "The effect of non-ablative laser energy on joint capsular properties: An in vitro 
mechanical study using a rabbit model," Am. J. Sports Med. 23, pp. 482-487, 1995.

82. K. Hayashi, G. Thabit III, J. J. Bogdanske, L. N. Mascio, M. D. Markel, "The effect of nonablative laser energy on the ultrastructure of joint capsular collagen," Arthroscopy. 12, pp. 474-481, 1996.

83. K. Hayashi, G. Thabit III, A. C. Vailas, J. J. Bogdanske, A. J. Cooley, M. D. Markel, "The effect of non-ablative laser energy on joint capsular properties: An in vitro histological and biochemical study using a rabbit model," Am. J. Sports Med. 24, pp. 640-646, 1996.

84. S. L. Schaefer, M. J. Ciarelli, S. P. Arnoczky, H. E. Ross, "Tissue shrinkage with the holmium:yttrium aluminum garnet laser: A postoperative assessment of tissue length, stiffness, and structure," Am. J. Sports Med. 25, pp. 841-848. 1997.

85. K. Hayashi, G. Thabit III, K. L. Massa, J. J. Bogdanske, A. J. Cooley, J. F. Orwin, M. D. Markel, "The effect of thermal heating on the length and histologic properties of the glenohumeral joint capsule," Am. J. Sports Med. 25, pp. 107-112, 1997.

86. G. S. Naseef, T. E. Foster, K. Trauner, S. Solhpour, R. R. Anderson, B. Zarins, "The thermal properties of bovine joint capsule," Am. J. Sports Med. 25, pp. 670-674, 1997.

87. C. T. Vangsness, W. Mitchell III, M. Nimni, M. Erlich, V. Saadat, H. Schmortzer, "Collagen shortening: An experimental approach with heat," Clin. Orthop. 337, pp. 267-271, 1997.

88. M. S. Wall, X. Deng, P. A. Torzilli, S. B. Doty, S. J. O'Brien, R. F. Warren, "Thermal modification of collagen," J. Shoulder Elbow Surg. 8, pp. 339-344, 1999.

89. K. Hayashi, D. M. Peters, G. Thabit III, P. Hecht, R. Vanderby, G. S. Fanton, M. D. Markel, "The mechanism of joint capsule thermal modification in an in vitro sheep model," Clin. Orthop. 1999.

90. S. Nath, J. P. DiMarco, D. E. Haines, "Basic aspects of radiofrequency catheter ablation," J. Cardiovasc. Electrophysiol. 5, pp. 863-876, 1994.

91. M. H. Seegenschmiedt, R. Sauer, "The current role of interstitial thermoradiotherapy," Strahlenther. Onkol. 168, pp. 119-140, 1992.

92. G. Bonin, W. W. Alberts, E. W. Wright, B. Feinstein, "Radiofrequency brain lesions," Archs. Neurolog. 12, pp. 25-29, 1965.

93. A. H. Meier, E. H. Weil, E. S. van Waalwijk van Doorn, G. T. Verhaegh, R. A. Janknegt, "Transurethral radiofrequency heating or thermotherapy for benign prostatic hyperthrophy," European Urology. 22, pp. 39-43, 1992.

94. R. A. Schachar, "Radial thermokeratoplasty," Int. Ophthalmol. Clin. 31, pp. 4757, 1990.

95. S. L. Obrzut, P. Hecht, K. Hayashi, G. S. Fanton, G. Thabit III, M. D. Markel, "The effect of radiofrequency energy on the length and temperature profiles of the glenohumeral joint capsule," Arthroscopy. 14, pp. 395-400, 1998.

96. M. J. Lopez, K. Hayashi, G. S. Fanton, G. Thabit III, M. D. Markel, "The effect of radiofrequency energy on the ultrastructure of joint capsular collagen," Arthroscopy. 14, pp. 495-501, 1998.

97. M. J. Lopez, K. Hayashi, R. Vanderby, G. Thabit III, G. S. Fanton, M. D. Markel, "Effects of monopolar radiofrequency energy on ovine joint capsular mechanical properties," Clin. Orthop. 1999. 
98. C. Osmond, P. Hecht, K. Hayashi, S. Hansen, G. S. Fanton, G. Thabit III, M. D. Markel, "Comparative effects of laser and radiofrequency energy on joint capsule," Clin. Orthop. 1999 (submitted).

99. M. T. Selecky, C. T. Vangsness, W. L. Liao, V. Saadat, T. P. Hedman, "The effect of laser-induced collagen shortening on the biomechanical properties of the inferior glenohumeral ligament complex," Am. J. Sports Med. 27, pp. 168$172,1999$.

100. A. Ferrara, W. L. Liao, J. Itamura, T. Hedman, C. T. Vangsness, "The biomechanical effects of radiofrequency induced collagen shortening on the inferior glenohumeral ligament complex," American Orthopaedic Society for Sports Medicine 1999, Anaheim, CA, pp. 34, 1999.

101. A. Deutsch, P. Protomastro, J. E. Barber, B. N. Victoroff, "The biomechanical effects of thermal capsulorrhaphy on the kinematic properties of the glenohumeral joint," American Orthopaedic Society for Sports Medicine 1999, Anaheim, CA, pp. 33, 1999.

102. J. E. Tibone, P. J. McMahon, T. A. Shrader, M. D. Sandusky, T. Q. Lee, "Glenohumeral joint translation after arthroscopic, nonablative, thermal capsulorrhaphy with a laser," Am. J. Sports Med. 26, pp. 495-498, 1998.

103. J. E. Tibone, P. I. McMahon, T. A. Shrader, A. D. Black, M. D. Sandusky, T. Q. Lee, "Glenohumeral translation after thermal capsulorrhaphy: A comparison of application with laser and radiofrequency," Trans. Orthop. Res. Soc. 23, pp. $735,1998$.

104. K. Hayashi, P. Hecht, G. Thabit III, D. M. Peters, R. Vanderby, A. J. Cooley, G. S. Fanton, J. F. Orwin, M. D. Markel, "The biological response to laser thermal modification in an in vivo sheep model," Clin. Orthop. 1999.

105. T. F. Schlegel, "The effect of postoperative immobilization on the healing of radiofrequency heat probe modified tissue," American Orthopaedic Society for Sports Medicine 1999, Anaheim, CA, pp. 31, 1999.

106. A. L. Wallace, R. M. Hollinshead, C. B. Frank, "Creep behavior of a lapine model of ligament laxity after electrothermal shrinkage in vivo," American Orthopaedic Society for Sports Medicine 1999, Anaheim, CA, pp. 32, 1999.

107. S. P. Arnoczky, "Basic science of thermal shrinkage," American Orthopaedic Society for Sports Medicine 1999, Anaheim, CA, pp. 37, 1999.

108. K. Hayashi, K. L. Massa, G. Thabit III, G. S. Fanton, M. F. Dillingham, K. W. Gilchrist,, M. D. Markel, "Histologic evaluation of the glenohumeral joint capsule after the laser-assisted capsular shift procedure for glenohumeral instability," Am. J. Sports Med. 27, pp. 162-167, 1999.

109. A. D. Frogameni, P. Stanton, S. R. Saddemi, C. Foetisch, P. J. Fenton, "Arthroscopic laser capsulorrhaphy for symptomatic laxity," American Orthopaedic Society for Sports Medicine 1999, Anaheim, CA, pp. 35, 1999

110. F. H. Savoie, P. L. Griffith, "Laser assisted capsulorrhaphy in multidirectional shoulder instability: A two year comparison with arthroscopic capsular shift," Arthroscopic Association of North America 1999, Anaheim, CA, 1999

111. G. S. Fanton, "Arthroscopic electrothermal surgery of the shoulder," Arthroscopy and Reconstructive Surgery 1999, Sun Valley, ID, 1999.

112. J. R. Andrews, "Radiofrequency thermal shrinking in throwing athletes," American Orthopaedic Society for Sports Medicine 1999, Anaheim, CA, pp. 4243, 1999.

113. D. F. D'Alessandro, "Thermal capsulorrhaphy. Does it work for MDI?" American Shoulder and Elbow Surgeons 1999, Anaheim, CA, 1999. 
114. R. F. Warren, "Thermal capsulorrhaphy. Where am I today?" American Shoulder and Elbow Surgeons 1999, Anaheim, CA, 1999.

115. G. Thabit III, "Arthroscopic monopolar radiofrequency treatment of chronic anterior cruciate ligament instability," Operative Techniques in Sports Medicine, D. Drez and J.C. DeLee, 6, pp. 157-160, W.B. Saunders Company, Philadelphia, 1998.

116. M. Dillingham, "Arthroscopic electrothermal surgery of the knee," Operative Techniques in Sports Medicine, D. Drez and J.C. DeLee, 6, pp. 154-156, W.B. Saunders Company, Philadelphia, 1998.

117. J. P. Warner, "Clinical concerns with tissue shrinkage: Where does it fit into clinical practice?" American Orthopaedic Society for Sports Medicine 1999, Anaheim, CA, pp. 45, 1999. 